\title{
Japanese go it alone with earthquake prediction
}

Tokyo. A new five-year plan for earthquake prediction is expected to be approved tomorrow ( 30 July) by a committee of Japan's Ministry of Education, Science and Culture (MESC). But despite more than 18 months of controversy, it differs little from the previous plan.

Japan's earthquake prediction programme was launched in the $1960 \mathrm{~s}$, and has cost more than $\$ 1$ billion and involved more than 500 scientists. Its credibility was shaken last year, when scientists - some working on the programme - questioned its underlying principles. They also criticized the fact that the programme was reviewed by its founders (see Nature 356, 464; 1992).

In May, six independent experts reviewed an internal report on the present six-year plan which ends next March. These included Masuo Ida, a former official of the education ministry and a vocal critic of the programme, Saburo Nagakura, president of the Graduate University for Advanced Studies, and heads of the volcanological and seismological societies of Japan.

The next five-year plan was reviewed a few weeks ago by outside experts, but they did not include the most vocal critics from the previous review. The final plan incorporates none of the criticisms made in the latest closed external review.

When Japan started its programme, many scientists worldwide believed that earthquakes could be predicted by collecting vast amounts of empirical data and sifting these for "precursors". The United States has now abandoned all but a small prediction programme in California, and spends most money and effort on disaster mitigation. But leaders of Japan's programme insist they will soon be able to predict earthquakes.

One of the plan's few new elements is a call for research on "evaluation of the potential of earthquake occurrence". This seems to mean assessment of where earthquakeprone regions are within "the cycle" of major earthquake events. This idea has been around for years. Critics say it is flawed because earthquakes do not occur in regular cycles, and it is impossible to position a region within a cycle beyond making generalized forecasts based on plate tectonics.

Members of the drafting committee who opposed this call were overruled by programme founders. One scientist close to the drafting process says the reason seems to be "to continue to trick the Japanese public into thinking earthquake prediction is possible."

What is new is a call for more oceanbottom observations: more than four-fifths of earthquakes in Japan occur under the sea. But the report does not say where the new ocean-bottom stations will be. Scientists are divided on the matter: one group favours a site at the junction of the Kurile and Japan trenches off Hokkaido island in the North, while another, led by Tomowoo Hirosawa of Tohoku University, wants them around a platform in a gas field off the coast of Fukushima Prefecture near the university.

Although two major earthquakes have hit the Japan Sea over the past decade with serious loss of life, the report does not define new areas where observations should be intensified or define new regions for intensified earthquake observation. After an earthquake hit the Japan Sea two weeks ago, Kiyoo Mogi, head of the coordinating com-
Volcano plans

By comparison, Japan's next five-year programme for volcanic eruption - to be announced the same day as the earthquake plan - seems almost radical. It designates regions for intense observation, such as the area around Mount Unzen which erupted in June 1991 and continues to erupt. It also calls for greater emphasis on basic research on magma chambers and the movement of magma, instead of collecting vast amounts of empirical data for prediction. D.S.

mittee for earthquake prediction, told the press that it might designate the region for special observation in the next five-year plan. This now seems unlikely.

David Swinbanks

\section{Britain to support aerospace}

London. Aerospace is likely to become one of the first industrial sectors to benefit from the British government's new-found enthusiasm for aligning science funding with a consensus view of industry's long-term needs.

Tim Sainsbury, minister for industry, announced last week that the Department of Trade and Industry (DTI) will discuss with other government departments how to identify the priority needs of the aerospace industry, and how to meet them. The public consultation will include those with responsibility for publicly funded aviation research programmes in bodies ranging from the Science and Engineering Research Council (SERC) to the Ministry of Defence.

The move follows claims from the aerospace industry that a collapse in military and civilian orders has undermined its capacity to invest in long-term research. Such research, it says, is essential to its long-term prosperity (see Nature 362,$484 ; 1993$ ). It is also consistent with the government's future approach to research funding outlined in the recent white paper (policy document).

The House of Commons Select Committee on Science and Technology last week backed industry's call that the government should support research in key technologies. The committee claimed that the United States and other European governments in particular France and Germany - spend much more than Britain on backing their aerospace industries. It urged the government to increase funding for research and technology "sufficient to maintain the UK industry's technological competitiveness".

The DTI has studiously avoided any financial commitment. It recently decided to stop funding industrial research directly through the Advanced Technology Programme, run jointly with the SERC. But Sainsbury's announcement indicates that the government has responded more positively to another recommendation of the select committee: that it should design a "single national technology acquisition plan" covering the technology needs of both civil and military sectors.

The government's statement is the first significant example of DTI's desire to take a more interventionist approach to industrial policy. In particular, Sainsbury expressed support for the principles behind a ten-year initiative, known as the National Strategic Technology Acquisition Plan, (NSTAP) drawn up by a committee of industry and academic advisers.

The plan identifies three categories of technology which, it says, UK industry will need over the next 20 years: fundamental technologies (such as advanced wing design) to provide competitive edge; "enhancing technologies" to improve the effectiveness of the industry; and supporting technologies imported from other sectors of industry.

According to officials from British Aerospace (BAe), the French government provides three times more research and development support to its domestic aerospace industry than Britain does, and Germany provides even more. The NSTAP, reflecting the views of companies such as BAe and Westland, urges the DTI to quadruple its own spending on research and technology acquisition in the field, from the current level of $£ 22$ million a year to about $£ 100$ million a year for the next ten years.

If SERC gets involved, it will probably be through its new Innovative Manufacturing Initiative. This is run under the auspices of a committee headed by Stewart Miller, director of engineering and technology at Rolls Royce. The SERC has already said aviation technology will be part of the IMI's core research programme. David Dickson 